Article

\title{
Preparation and Properties of Sodium Carboxymethyl Cellulose/Sodium Alginate/Chitosan Composite Film
}

\author{
Wenting Lan ${ }^{1}$, Li He ${ }^{1, *}$ and Yaowen Liu ${ }^{1,2, *}$ \\ 1 College of Food Science, Sichuan Agricultural University, Ya'an 625014, China; WTLan@163.com \\ 2 School of Materials Science and Engineering, Southwest Jiaotong University, Chengdu 610031, China \\ * Correspondence: helifood@163.com (L.H.); lyw@my.swjtu.edu.cn (Y.L.); Tel.: +86-835-8763-4068 (Y.L.)
}

Received: 1 July 2018; Accepted: 12 August 2018; Published: 19 August 2018

\begin{abstract}
A sodium alginate/chitosan solution was prepared by dissolving sodium alginate, chitosan, and glycerol in an acetic acid solution. This solution was then combined with a sodium carboxymethyl cellulose solution and the mixture was cast onto a glass plate and dried at a constant temperature of $60^{\circ} \mathrm{C}$. Then, a carboxymethyl cellulose/sodium alginate/chitosan composite film was obtained by immersing the film in a solution of a cross-linking agent, $\mathrm{CaCl}_{2}$, and air-drying the resulting material. First, the most advantageous contents of the three precursors in the casting solution were determined by a completely random design test method. Thereafter, a comprehensive orthogonal experimental design was applied to select the optimal mass ratio of the three precursors. The composite film obtained with sodium alginate, sodium carboxymethyl cellulose, and chitosan contents of $1.5 \%$, $0.5 \%$, and $1.5 \%$, respectively, in the casting solution displayed excellent tensile strength, water vapor transmission rate, and elongation after fracture. Moreover, the presence of chitosan successfully inhibited the growth and reproduction of microorganisms. The composite film exhibited antibacterial rates of $95.7 \% \pm 5.4 \%$ and $93.4 \% \pm 4.7 \%$ against Escherichia coli and Staphylococcus aureus, respectively. Therefore, the composite film is promising for antibacterial food packaging applications.
\end{abstract}

Keywords: sodium carboxymethyl cellulose; sodium alginate; chitosan; antimicrobial packaging

\section{Introduction}

With continuously intensifying environmental pollution and a gradual increase in environmental awareness, the development of novel green materials to reduce the use of plastics has become popular. The use of composite films prepared from natural materials is not only safe and environmentally friendly, but also enables full utilization of the properties of the raw materials by compensating for any shortcomings of the individual components and thus increasing their value for practical applications. The use of composite films for food packaging applications helps reduce the adverse effects of using plastic bags, such as fossil fuel consumption and soil and water pollution [1,2]. Targeted selection of raw materials can allow the fabrication of composite films with special properties, such as antibacterial properties and biodegradability [3,4], making them effective for food packaging applications.

Cellulose is the most abundant renewable and biodegradable material found in nature [5]. However, it has limited application because it is insoluble in water as well as in common organic and inorganic solvents. Sodium carboxymethyl cellulose (CMC) is a modified cellulose obtained through its carboxymethylation. CMC has an excellent film-forming ability, is biodegradable, and has low toxicity. Moreover, it has strong hydrophilicity and a stable internal network structure. These properties can be used to improve the performance of composite films [6,7]. Sodium alginate (SA) is a type of biopolymer that is extracted from brown seaweed. Because of its wound-healing properties, good moisture absorption and permeability, high viscosity in aqueous solutions, and other characteristics, SA has been widely used in biomedical applications and for fabricating new 
materials $[8,9]$. SA films have high mechanical strength; however, its poor moisture resistance hinders their wide application [10]. Chitosan (CS) is produced by the deacetylation of chitin, which is the main component of the exoskeleton of some crustaceans (such as crabs). CS, which is biodegradable, non-toxic, and potentially antibacterial, has been used extensively in biomedical applications, including tissue engineering [11]. The use of CS for fabricating new materials has also produced notable results.

In the process of selling goods, packaging plays a decisive role in protection, transportation, and sales promotion. Traditional packaging cannot keep up with the needs of social development in inhibiting microbial growth. Antibacterial (AM) packaging has attracted widespread attention in the industry in terms of extending shelf life and ensuring food safety. Antibacterial packaging is a food packaging prepared from green packaging materials and natural antibacterial agents to inhibit microbial growth. AM agents include essential oils, bacteriocins, enzymes, etc. Chitosan is useful in the field of antibacterial packaging research because of its non-toxic, degradable, and antibacterial properties [12]. Since SA, CMC, and CS have many advantages, these three materials are widely used in the preparation of AM packages, thereby generating a large amount of reference data on new composite materials. Wang et al. [13] added the quaternary ammonium salt of chitosan (HTCC) to a CMC film and obtained the best mechanical properties for a HTCC/CMC mass ratio of $10.0 \%$, which produced the strongest intermolecular interactions within the film. Moreover, scanning electron microscopy and infrared spectroscopy analyses studies revealed the interaction between HTCC and CMC to be strong, and that chitosan derivatives helped enhance the mechanical properties of the composite film. Han et al. [14] used SA and CMC as raw materials and added antibacterial cinnamon essential oil (CEO) to formulate a SA/CMC/CEO film. The obtained composite film showed notable antibacterial properties against Escherichia coli (E. coli) and Staphylococcus aureus (S. aureus). Moreover, because CEO is a volatile substance with an unpleasant odor and a short-term effect, the application of this type of composite films in the fruit and food industry has been greatly limited. Therefore, CS, which is characterized by its long-lasting action, high adherence, and antibacterial properties, is an optimal additive for formulating composite films for practical applications. Kawasaki et al. [15] prepared a CS/CMC nanofiber composite film, and demonstrated that the addition of CS effectively inhibited the growth and adhesion of bacteria, showing a vast potential for biomedical material applications. Further, Noshirvani et al. [16] studied the influence of cinnamon and ginger essential oils on the physical and chemical properties of CS/CMC films. The results revealed that the added essential oils enhanced the moisture permeability and concurrently preserved the antibacterial properties of the CS/CMC film, which is important for food preservation. However, because essential oils have short-term effects, it is important to combine them with SA and CS/CMC films, which have high moisture absorption and permeability and long durability. Zhuang et al. [17] studied on double-layered nanofilms of polyvinyl alcohol (PVA)/CS/SA in which a PVA/CS film was used as the outer film and an SA film was used as the inner film. Their investigation revealed that within a certain range of concentration, the SA content improved the tensile strength of the double-layered film. Bajpai at al. [18] investigated the release of curcumin in CS/CMC composite films and found that the tensile strength increased with an increase in the CMC content, with the CMC crystals exhibiting self-reinforcement and interactions between the polar groups, which enhanced the interaction with the CS chains, and thus increased the tensile strength of the composite film.

However, studies on ternary CMC/SA/CS composite films have not yet been reported. In this study, the good moisture absorption and permeability, ductility, and film-forming ability of SA [19], the high strength of $C M C$, and the antibacterial properties of CS were combined to prepare an antibacterial CMC/SA/CS composite film via a casting method. In addition, the effects of the preparation technique and the change in the contents of the three components on the properties of the composite film were studied. Accordingly, the results of a completely randomized design test were combined for an orthogonal experimental design to investigate the optimal contents and proportions of CMC, SA, and CS to achieve optimal mechanical properties, moisture absorption, and other characteristics of the 
composite film. Finally, the results of the orthogonal experimental design were combined with those of the antibacterial property test to obtain a film that can be used for food packaging applications.

\section{Materials and Methods}

\subsection{Materials and Instrument}

CS (edible, degree of acetylation $\geq 90 \%$ ) was purchased from Zhuhai Weijia Food Additive Co., Ltd. (Zhuhai, China). SA and CMC (edible) as well as glycerol, glacial acetic acid, and anhydrous calcium chloride (analytically pure) were purchased from Chengdu Kelong Chemical Reagent Factory (Chengdu, China).

\subsection{Preparation of $C M C / S A / C S$ Composite Films}

The CMC having a mass of $0.5,1.0,1.5$, and $2.0 \mathrm{~g}$, respectively, was weighed into a beaker, and $100 \mathrm{~mL}$ of distilled water was added. The mixture was stirred with a magnetic stirrer (DJ1-40, Jiangsu Maipulong Instrument Manufacturing Co., Ltd., Changzhou, China) in a constant temperature water bath at $60^{\circ} \mathrm{C}$ until the CMC was completely dissolved. SA (0.5, 1.0, 1.5, and $\left.2.0 \mathrm{~g}\right), \mathrm{CS}(0.5,1.0,1.5$, and $2.0 \mathrm{~g})$ and glycerin $(1.0 \%, w / v$, the same as below) were weighed into a beaker, and $2.0 \%$ acetic acid solution $100 \mathrm{~mL}$ was added to the mixture and stirred in a water bath. Constant temperature $40{ }^{\circ} \mathrm{C}$ until SA and CS are completely dissolved. The solution was allowed to stand for $12 \mathrm{~h}$ for deaeration. The obtained solution was then mixed with the CMC solution at a mass ratio of 17:3, and stirred magnetically for $30 \mathrm{~min}$. Subsequently, films of the liquid was cast on a glass plate and baked for $10 \mathrm{~h}$ in a drying oven at $60^{\circ} \mathrm{C}$. After that, the film was removed from the oven and cooled at room temperature. Then, the film was soaked in $2.0 \% \mathrm{CaCl}_{2}$ solution for $2 \mathrm{~min}$, retrieved and laid flat on a glass plate and allowed to dry at room temperature to obtain the CMC/SA/CS composite film. Finally, put it into an artificial climate chamber (temperature is $25^{\circ} \mathrm{C}$, relative humidity is $50 \%$ ) and balance for $24 \mathrm{~h}$.

\subsection{Thickness}

A film sample that was smooth, unbroken, and had a relatively uniform thickness was selected and cut it into strips $(80 \mathrm{~mm} \times 15 \mathrm{~mm})$, and the thickness of each strip was measured at 5 points using a thickness gauge (YHT-127, Shenzhen Yuanhengtong Instrument and Meter Co., Ltd., Shenzhen, China). The measurements were recorded and the average thickness was calculated [20].

\subsection{Light Transmittance}

A smooth and undamaged film sample was selected and cut it into strips ( $30 \mathrm{~mm} \times 10 \mathrm{~mm}$ ) and adhered on one side of a dry glass cuvette. Then, their absorbance was measured at a wavelength of $600 \mathrm{~nm}$ on a spectrophotometer (756PC, Shanghai Haoyu Hengping Scientific Instrument Co., Ltd., Shanghai, China) using a dry, clean, and clear glass cuvette as the control. Record the measurements and calculate the average value [21].

\subsection{Water Absorption}

Water absorption was determined using the Ercelik method [22]. A film sample was cut into patches $(20 \mathrm{~mm} \times 20 \mathrm{~mm}$ ), which were then placed in separate beakers, each containing $20 \mathrm{~mL}$ of distilled water. After $24 \mathrm{~h}$, the patch surfaces were blotted using a paper towel and their weights were recorded as $W_{1}$. Next, the samples were dried at a constant temperature in an oven until a consistent weight was obtained, which was recorded as $W_{2}$. The moisture absorption was calculated using the following equation:

$$
W=\left(W_{1}-W_{2}\right) / W_{2} \times 100 \%
$$


where $W$ is the water absorption (\%), $W_{1}$ is the film weight after immersion and blotting the surface dry $(\mathrm{g})$, and $W_{2}$ is the film weight after drying $(\mathrm{g})$.

\subsection{Moisture Permeability Coefficient}

A smooth and undamaged film sample was selected and cut into circles using a round sampler $\left(33 \mathrm{~cm}^{2}\right)$, and the thickness of each circular film sample was measured using a thickness gauge at five appropriate points. After calculating their average thicknesses, they were input into a computer. The samples were placed sequentially into a water-permeable cup (PERME W3-031, Jinan Languang Electromechanical Technology Co., Ltd., Jinan, China), loaded into a water vapor transmission rate tester for $24 \mathrm{~h}$, and the measurements recorded [23].

\subsection{Tensile Strength}

A smooth and undamaged film sample was selected, cut into strips (80 $\mathrm{mm} \times 150 \mathrm{~mm})$, and then secured vertically on a texture analyzer probe (WDW-D, Jinan Wenteng Test Instrument Co., Ltd., Jinan, China). The installation parameters are as follows: a return distance of $60 \mathrm{~mm}$, a speed of $5 \mathrm{~mm} / \mathrm{s}$, an effective elongation distance of $80 \mathrm{~mm}$, and a trigger force of $5 \mathrm{~N}$. The maximum tensile force and displacement of the sample strips that cracked in the middle during the experiment were recorded. The analysis was carried out on three parallel groups of each sample and the mean values are reported [24]. The tensile strength was calculated using the following equation:

$$
T_{\mathrm{S}}=\left(F \times 10^{-6}\right) / S
$$

where $T_{\mathrm{S}}$ is the tensile strength $(\mathrm{MPa}), F$ is the maximum tensile force when the sample fractures $(\mathrm{N})$, and $S$ is the cross-sectional area of the sample (width $\times$ thickness; $\mathrm{m}^{2}$ ).

\subsection{Elongation after Fracture}

The displacement, $L$, which corresponds to the maximum tension during the tensile strength measurement, was calculated using the following equation:

$$
E=L / L_{0} \times 100 \%
$$

where $E$ is the elongation after fracture (\%), $L$ is the displacement corresponding to the maximum tensile force when the film fractures $(\mathrm{mm})$, and $L_{0}$ is the relative distance of the texture analyzer probe, that is, the return distance $(\mathrm{mm})$.

\subsection{Oil Permeability Coefficient}

A test tube was loaded with $5 \mathrm{~mL}$ of edible oil and sealed with a film sample. The sealed test tube was inverted and placed on a clean filter paper. The test tube was fixed at the center onto the sidewall and left for 3 days. Thereafter, the filter paper was weighed using an electronic scale, and the oil permeability coefficient was calculated using the following equation:

$$
P_{0}=(\Delta W \times F T) /(S \times T)
$$

where $P_{0}$ is the oil permeability coefficient $\left(\mathrm{g} \cdot \mathrm{mm} /\left(\mathrm{m}^{2} \cdot\right.\right.$ day $), \Delta W$ is the change in filter paper mass fraction (g); $F T$ is the film thickness $(\mathrm{mm}), S$ is the film area $\left(\mathrm{m}^{2}\right)$, and $T$ is the sample placement time (days).

\subsection{Surface Morphology}

The surface morphology of the composite film was observed using a scanning electron microscope (COXEM/EM-20, Korea COXEM Corporation, Wuxi, China) with an acceleration voltage of $20 \mathrm{kV}$. Before the observation, the film was cut into small flakes with dimensions of $2 \times 5 \mathrm{~mm}^{2}$, and both sides of each flake were glued onto a clean, circular metal tray. Finally, a thin layer of gold was sprayed 
uniformly on the surface of the film under vacuum, and the gold-coated surface was observed under the electron microscope [25].

\subsection{Infrared Spectroscopy Analysis}

An infrared spectrometer (FTIR-650, Suzhou Leiden Scientific Instrument Co., Ltd., Suzhou, China) was used to analyze the surface functional groups of the film at 32 scans in the measurement range of $500-4000 \mathrm{~cm}^{-1}$ at a resolution of $4 \mathrm{~cm}^{-1}$ [26].

\subsection{Antibacterial Testing}

For the antibacterial tests, S. aureus (S. aureus PTCC 1112) and E. coli (E. coli PTCC 1270) representing Gram-positive and Gram-negative bacteria, respectively, were selected. Firstly, all samples of films were irradiated with UV light to kill bacteria. The film samples ( $1 \mathrm{~g}$ of each sample) from the experimental group and the control group were cut into pieces and placed into different Erlenmeyer flasks. Then, growth medium $(50 \mathrm{~mL})$ and the bacterial strains $(1 \mathrm{~mL})$ were added. Next, the experimental group and the control group samples were shake-cultured at $37^{\circ} \mathrm{C}$ for $24 \mathrm{~h}$. A flask containing bacteria and the SA film sample was used as a control. After incubating for $24 \mathrm{~h}, 1 \mathrm{~mL}$ of bacterial culture was taken out from the flask, and serial dilutions were repeated with each initial sample. Then, $0.1 \mathrm{~mL}$ diluent of the sample was spread onto nutrient agar plates and incubated at $37^{\circ} \mathrm{C}$ for $24-48 \mathrm{~h}$. Finally, the bacterial colonies were counted and recorded as the after-culture bacteria count. The antibacterial rate was calculated and averaged [27]:

$$
\text { Mortality }(\%)=(B-A) / B \times 100 \%
$$

where $B$ and $A$ are the mean number of bacteria in the control samples and the treated samples after $24 \mathrm{~h}$ incubation, respectively.

\section{Results and Discussion}

\subsection{Results of the Completely Randomized Design}

Because food packaging materials are required to have high strength, the tensile strength was selected as the standard for the completely randomized design test [28]. The test results are shown in Table 1. For an increase in the SA content for a fixed CS and CMC contents of $1.0 \%$ and $1.5 \%$, respectively, in the casting solution, the thickness of the composite film increased continually, while the tensile strength first increased and then decreased. When the SA content was $1.5 \%$, the maximum tensile strength of $84.19 \pm 12.86 \mathrm{MPa}$ was achieved; however, the content had no significant effect on the elongation after fracture of the composite film. The high viscosity and film-forming ability of SA causes the molecules to link closely, decreasing the intermolecular spaces and increasing the tensile strength of the composite film [29]. The highest tensile strength was observed for an SA content of $1.5 \%$. When the SA content was less than $0.5 \%$, the solution was as transparent as water and had no film-forming ability. When the SA content exceeded $2.0 \%$, SA did not dissolve completely during the solution preparation process, and small air bubbles formed in the solution, which could not be removed, thus preventing the film formation. For comprehensive tensile strength testing, SA contents of $1.0 \%, 1.5 \%$, and $2.0 \%$ were selected for the orthogonal experimental design.

With a change in the CS content of the casting solution from $0.5 \%$ to $2.0 \%$ (with fixed SA and CMC contents of $1.0 \%$ and $1.5 \%$, respectively), the thickness of the composite film continued to increase, while the tensile strength and elongation after fracture changed minimally. Further, as the CS content increased, the tensile strength of the composite film increased slightly at first and then decreased. The maximum tensile strength was the maximum of $61.39 \pm 10.07 \mathrm{MPa}$ was achieved with a CS content of $1.5 \%$. For comprehensive tensile strength test, CS contents of $1.0 \%, 1.5 \%$, and $2.0 \%$ were selected for the orthogonal experimental design. 
With change in CMC content from $0.5 \%$ to $2.0 \%$ (with fixed SA and CS contents of $1.0 \%$, respectively), the thickness of the composite film did not change significantly, whereas the tensile strength first increased and then decreased. When the CMC content was $1.0 \%$, the maximum tensile strength of $78.23 \pm 11.74 \mathrm{MPa}$ was observed, while the cracking and elongation after fracture showed a fluctuating trend. More specifically, the tensile strength first decreased, then increased, and finally decreased again, with the maximum value reaching $9.56 \% \pm 2.17 \%$. Because of the low CMC content, which was only $15 \%$ of the mass of the composite membrane sample, the film thickness did not change significantly with a change in the CMC content. However, Because CMC has an internal sugar ring structure, it has a good skeleton effect as a composite structure, and it can improve the internal structural stability of the composite film, thus increasing the tensile strength and ductility of the composite film [30]. In order to obtain a composite film that has high tensile strength and good ductility, CMC contents of $0.5 \%, 1.0 \%$, and $1.5 \%$ were selected for the orthogonal experimental design. Although the ductility was good at $2.0 \% \mathrm{CMC}$, the tensile strength diminished. Therefore, this value was not used.

In summary, the single factor concentration range of SA, CMC and CS is $0.5 \%-2.0 \%$. This test is to control the thickness of the film by mass. During the experiment, it was found that when the concentration was less than $0.5 \%$, the composite film formed was very thin due to the too small amount of solute substances in the solution. As it is difficult to maintain the integrity of the film, the composite film is intended for use in food packaging. Thickness is a key parameter in determining film clarity, water permeability and mechanical properties, which increases the film's ability to improve the mechanical integrity of foods. When the concentration is greater than $2 \%$, when the solution is prepared, the solution reaches saturation, and the solute is difficult to completely dissolve. Therefore, no further experiments were continued. And within the concentration range of this experiment, the performance of the composite membrane showed a trend of increasing first and then less. The effect of concentration changes on the performance of the composite membrane has been well demonstrated. This concentration range is representative [28].

Table 1. The results of complete randomized design.

\begin{tabular}{cccc}
\hline Samples & Thickness $(\boldsymbol{\mu m})$ & Tensile Strength $(\mathbf{M P a})$ & Elongation After Fracture $(\mathbf{\%})$ \\
\hline SA-0.5\% & $53.7 \pm 1.10$ & $46.48 \pm 6.57$ & $6.15 \pm 1.07$ \\
SA-1.0\% & $67.3 \pm 1.60$ & $59.39 \pm 9.89$ & $5.03 \pm 0.75$ \\
SA-1.5\% & $74.1 \pm 2.10$ & $84.19 \pm 12.86$ & $6.44 \pm 1.16$ \\
SA-2.0\% & $97.8 \pm 2.80$ & $67.21 \pm 10.33$ & $7.67 \pm 1.31$ \\
CS-0.5\% & $59.4 \pm 1.40$ & $54.59 \pm 7.55$ & $4.47 \pm 0.52$ \\
CS- $1.0 \%$ & $67.3 \pm 1.50$ & $59.39 \pm 9.86$ & $5.03 \pm 0.91$ \\
CS- $1.5 \%$ & $85.5 \pm 2.50$ & $61.39 \pm 10.07$ & $5.43 \pm 0.86$ \\
CS- $2.0 \%$ & $112.7 \pm 3.10$ & $54.18 \pm 7.59$ & $5.68 \pm 0.91$ \\
CMC-0.5\% & $70.2 \pm 1.90$ & $56.12 \pm 8.89$ & $9.56 \pm 2.17$ \\
CMC-1.0\% & $65.4 \pm 1.50$ & $78.23 \pm 11.74$ & $5.20 \pm 0.81$ \\
CMC- $-1.5 \%$ & $67.6 \pm 1.60$ & $59.39 \pm 9.86$ & $5.03 \pm 0.75$ \\
CMC-2.0\% & $74.9 \pm 2.20$ & $59.51 \pm 9.59$ & $8.98 \pm 1.51$ \\
\hline
\end{tabular}

\subsection{Results of Orthogonal Experiment}

Based on the results of the completely randomized design test, a comprehensive orthogonal experimental design was carried out using a combination of SA (content: $1.0 \%, 1.5 \%$, and $2.0 \%$ ), CS (content: $1.0 \%, 1.5 \%$, and $2.0 \%$ ), and CMC (content: $0.5 \%, 1.0 \%$, and $1.5 \%$ ). Moreover, the tensile strength, elongation after fracture, and other indices were determined. SA, CS, and CMC were used as the test factors, while the tensile strength, elongation after fracture, water absorption, oil permeability coefficient, moisture permeability coefficient, and transparency were the tested parameters. The orthogonal experimental design factors and parameters are shown in Table 2. 
Table 2. The factors and levels of orthogonal experimental design.

\begin{tabular}{cccc}
\hline \multirow{2}{*}{ Level } & \multicolumn{3}{c}{ Factors } \\
\cline { 2 - 4 } & SA (\%) & CS (\%) & CMC (\%) \\
\hline 1 & 1.0 & 1.0 & 0.5 \\
2 & 1.5 & 1.5 & 1.0 \\
3 & 2.0 & 2.0 & 1.5 \\
\hline
\end{tabular}

The results of the orthogonal experimental design were processed and analyzed based on a reference. According to the raw data, a series of the performance indicators of the nine composite membranes are arranged in sequence. The best performance score is 10 points, and the worst is 1 point. The scores of the nine composite membranes were calculated according to the proportions. All performance scores were added to get the total score; according to the factors, the total scores were averaged to obtain $\mathrm{K}$. According to the factors, the scores of a certain performance were added and arranged in sequence, and the degree of the influence of the factors on the performance can be judged [31]. Because the composite film is intended for food packaging applications, it is required to have high strength and ductility. The higher the tensile strength and the elongation after fracture, the better is the film [18]. Moreover, since food packaging often comes into contact with water and oils, the lower the water absorption, oil permeability coefficient, and moisture permeability coefficient, the better the composite film. In addition, the film should have high light transmittance so that the packaging contents can be clearly visible [31,32]. Table 3 shows the results of the orthogonal experimental design. Table 4 shows the raw data of the composite film, and Table 5 shows the grading results for the individual factors. It is evident from Table 3 that the composite film 3, with the highest score, has the optimal physical performance. Table 3 also indicates the following primary and secondary relationships between the factors that affect the comprehensive performance of the composite film: $\mathrm{B}>\mathrm{A}>\mathrm{C}$, which is $\mathrm{CS}>\mathrm{SA}>\mathrm{CMC}$. When the CS, SA, and CMC contents are varied, the physical attributes of the composite film are mainly affected by CS and SA. The combination that results in the optimal comprehensive performance is $\mathrm{A} 2 \mathrm{~B} 2 \mathrm{C} 1$, that is, the composite film fabricated with SA, CS, and CMC contents of $1.5 \%, 1.5 \%$, and $0.5 \%$, respectively.

Table 3. The results of orthogonal experimental design $L_{9}(3)^{3}$.

\begin{tabular}{cccc}
\hline \multirow{2}{*}{ Level } & \multicolumn{3}{c}{ Factors } \\
\cline { 2 - 4 } & A & B & C \\
\hline 1 & $\mathrm{~A} 1$ & $\mathrm{~B} 1$ & $\mathrm{C} 1$ \\
2 & $\mathrm{~A} 1$ & $\mathrm{~B} 2$ & $\mathrm{C} 3$ \\
3 & $\mathrm{~A} 1$ & $\mathrm{~B} 3$ & $\mathrm{C} 2$ \\
4 & $\mathrm{~A} 2$ & $\mathrm{~B} 1$ & $\mathrm{C} 2$ \\
5 & $\mathrm{~A} 2$ & $\mathrm{~B} 2$ & $\mathrm{C} 2$ \\
6 & $\mathrm{~A} 2$ & $\mathrm{~B} 3$ & $\mathrm{C} 3$ \\
7 & $\mathrm{~A} 3$ & $\mathrm{~B} 1$ & $\mathrm{C} 3$ \\
8 & $\mathrm{~A} 3$ & $\mathrm{~B} 2$ & $\mathrm{C} 1$ \\
9 & $\mathrm{~A} 3$ & $\mathrm{~B} 3$ & $\mathrm{C} 1$ \\
K1 & 35.82 & 34.87 & 36.86 \\
K2 & 36.34 & 38.64 & 32.87 \\
K3 & 29.92 & 28.57 & 32.35 \\
$R$ & 6.42 & 10.07 & 4.51 \\
Optimal level & $\mathrm{A} 2$ & $\mathrm{~B} 2$ & $\mathrm{C} 1$ \\
\hline
\end{tabular}

A, B, and C stand for SA, CS, CMC; 1-9 represent the concentration combination of the composite film; K1, the total score of each factor in its first level; K2, the total score of each factor in its second level; $\mathrm{K} 3$, the total score of each factor in its third level; and $R$, the range score of each factor in its each level. 
Based on the data in Table 5, the primary and secondary relationships between the three factors based on their effects on each indicator were analyzed using a ranking score analysis, and the results are shown in Table 6.

Table 4. The raw data of orthogonal experimental test.

\begin{tabular}{ccccc}
\hline Samples & Thickness (mm) & Tensile Strength (MPa) & $\begin{array}{c}\text { Elongation after } \\
\text { Fracture (\%) }\end{array}$ & $\begin{array}{c}\text { Water Uptake } \\
\mathbf{( \% )}\end{array}$ \\
\hline 1 & $70 \pm 3.10$ & $56.12 \pm 2.11$ & $9.56 \pm 0.98$ & $2.83 \pm 0.12$ \\
2 & $75 \pm 2.90$ & $54.18 \pm 3.12$ & $5.68 \pm 0.36$ & $23.00 \pm 1.02$ \\
3 & $96 \pm 3.60$ & $69.95 \pm 2.07$ & $15.51 \pm 0.32$ & $12.50 \pm 0.89$ \\
4 & $97 \pm 4.00$ & $61.12 \pm 1.81$ & $30.46 \pm 0.13$ & $6.33 \pm 0.09$ \\
5 & $125 \pm 5.10$ & $49.55 \pm 1.98$ & $3.47 \pm 0.39$ & $6.00 \pm 0.13$ \\
6 & $134 \pm 4.20$ & $54.96 \pm 2.22$ & $13.05 \pm 0.87$ & $5.50 \pm 0.32$ \\
7 & $108 \pm 4.90$ & $62.34 \pm 2.43$ & $19.51 \pm 1.20$ & $2.75 \pm 0.17$ \\
8 & $129 \pm 4.90$ & $52.24 \pm 1.19$ & $7.35 \pm 0.69$ & $8.00 \pm 0.28$ \\
9 & $153 \pm 2.30$ & $84.19 \pm 0.53$ & $6.44 \pm 0.31$ & $4.00 \pm 0.03$ \\
\hline \hline & Oil Permeability & & Light & \\
Samples & Coefficient & & & \\
& $95 \pm 2.09$ & $1271.73 \pm 5.03$ & $71.85 \pm 1.07$ & \\
2 & $156 \pm 3.18$ & $1292.93 \pm 6.45$ & $68.39 \pm 3.56$ & \\
3 & $25 \pm 0.75$ & $1272.93 \pm 2.19$ & $23.50 \pm 2.13$ & \\
4 & $289 \pm 3.19$ & $1382.13 \pm 4.19$ & $33.34 \pm 0.19$ & \\
5 & $171 \pm 3.98$ & $1290.00 \pm 3.32$ & $54.20 \pm 2.00$ & \\
6 & $163 \pm 0.47$ & $1289.20 \pm 2.18$ & $82.22 \pm 3.13$ & \\
7 & $178 \pm 5.00$ & $1528.27 \pm 3.76$ & $97.05 \pm 2.50$ & \\
8 & $241 \pm 7.20$ & $1220.93 \pm 4.10$ & $55.72 \pm 1.72$ & \\
\hline
\end{tabular}

Table 5. The data of calculation.

\begin{tabular}{cccccccc}
\hline Samples & $\begin{array}{c}\text { Tensile } \\
\text { Strength }\end{array}$ & $\begin{array}{c}\text { Elongation } \\
\text { after } \\
\text { Fracture }\end{array}$ & $\begin{array}{c}\text { Water } \\
\text { Uptake } \\
\mathbf{( \% )}\end{array}$ & $\begin{array}{c}\text { Oil } \\
\text { Permeability } \\
\text { Coefficient }\end{array}$ & $\begin{array}{c}\text { Water } \\
\text { Permeability } \\
\text { Coefficient }\end{array}$ & $\begin{array}{c}\text { Light } \\
\text { Transmittance } \\
(\%)\end{array}$ & $\begin{array}{c}\text { Total } \\
\text { Score }\end{array}$ \\
\hline 1 & 2.71 & 3.01 & 9.87 & 7.60 & 8.44 & 8.14 & 39.77 \\
2 & 2.20 & 1.73 & 1.00 & 5.52 & 7.82 & 7.63 & 25.90 \\
3 & 6.30 & 4.97 & 5.62 & 10.00 & 8.40 & 6.49 & 41.78 \\
4 & 4.01 & 10.00 & 8.33 & 1.00 & 5.24 & 1.00 & 29.58 \\
5 & 1.00 & 1.00 & 8.48 & 5.01 & 7.91 & 2.20 & 25.60 \\
6 & 2.41 & 4.16 & 8.70 & 5.28 & 1.00 & 4.76 & 8.19 \\
7 & 4.33 & 6.29 & 10.00 & 4.77 & 10.00 & 33.24 \\
8 & 1.70 & 2.28 & 7.60 & 2.63 & 5.99 & 34.58 \\
9 & 10.00 & 1.98 & 9.36 & 9.30 & & 4.94 \\
\hline
\end{tabular}

Table 6. The analysis of film index.

\begin{tabular}{ccc}
\hline Index & The Relations of Affect & Range \\
\hline Tensile strength & $\mathrm{B}>\mathrm{C}>\mathrm{A}$ & $15.56>12.96>6.13$ \\
Elongation after fracture & $\mathrm{B}>\mathrm{A}>\mathrm{C}$ & $14.17>8.86>5.5$ \\
Water uptake & $\mathrm{B}>\mathrm{A}>\mathrm{C}$ & $9.14>7.75>6.33$ \\
Oil permeability coefficient & $\mathrm{A}>\mathrm{B}>\mathrm{C}$ & $120.67>83.33>20.33$ \\
Moisture Permeability Coefficient & $\mathrm{A}>\mathrm{B}>\mathrm{C}$ & $120.93>117.42>57.07$ \\
Light transmittance & $\mathrm{C}>\mathrm{A}>\mathrm{B}$ & $30.27>29.61>24.56$ \\
\hline
\end{tabular}

It is evident that the tensile strength is an important indicator of the cross-sectional tension of the composite film [28]. All the three test factors affected the tensile strength of the composite film. The central part of the molecular structure contained a large number of hydroxyl groups, which provided the necessary conditions for the formation of intermolecular hydrogen bonds and help increase the intermolecular forces. Both CS and CMC strongly affect the tensile strength of the composite film, while the viscous CS solution caused the molecules to bind more tightly, and CMC, which itself has a stable network structure, increased the tensile strength of the composite film. Bajpai et al. [18] proposed 
that as the CS content increases from $0 \%$ to $2.0 \%$, the tensile strength of the CS film increases by a factor of three. This is related to strengthening of the cellulose crystals and is associated with the interaction between the polar groups of the CMC and CS chains. The addition of CMC can enhance the tensile strength of the composite film, however, when the CMC content exceeds a certain limit, it reacts to the tensile strength. Atefa et al. [33] demonstrated that excessive super-hard stiffness and cracks in the film matrix are the main reasons leading to brittleness and reduced tensile strength of the film. However, Hu et al. [28] believe that some of the weak polymers replace the stronger polymers, thereby weakening the internal network structure of the film, and thus causing a decrease in the tensile strength. In addition, the cross-linking agent, $\mathrm{CaCl}_{2}$, can increase the tensile strength of the composite film within a certain range. Calcium ions form strong chemical bonds with $\mathrm{CMC}$, but they also continue to concentrate, which can cause the film to have uneven internal structure, which lowers its tensile strength. Contrast, the opposite occurs when SA cross-links with $\mathrm{CaCl}_{2}$. The SA content affected the tensile strength of the composite film indirectly. Elongation after fracture is an indicator of the composite film's toughness. An appropriate elongation is essential for improving the packaging adaptability, enhancing its protective quality, and ensuring that no breakage occurs when the packaging is folded. The elongation after fracture of the composite film in this study was mostly influenced by the CS content. CS molecules contain a large number of amino and hydrogen groups, which form strong hydrogen bonds and prevent molecular slip, thereby increasing the tensile strength of the composite film, but reduce its elongation capability [34]. The elongation after fracture was also influenced by the cross-linking agent, $\mathrm{CaCl}_{2}$, which destroys the $\mathrm{CS}$ and SA hydrogen bonds, thus lowering their crystallinity. The higher the crystallinity, the stronger the intermolecular force, which increases the tensile strength of the material; however, it reduces the properties related to molecular action, such as the elongation rate. The cross-linking agent reduces the tensile strength of the composite film, while increasing its elongation after fracture. This is similar to the conclusions of [35]. Ebrahimi et al. [32] believe that glycerin is the most common plasticizer that reduces the intermolecular forces between polymers. This results in a decrease in the tensile strength and an increase in the elongation at break.

The water absorption and moisture permeability coefficients of a film are related to the hydrophilicity of the molecules. Ebrahimi et al. [32] clearly pointed out that WVP is one of the important indicators to avoid mass transfer between food and the surrounding environment within the membrane. Furthermore, Kanmani et al. [36] suggested that it is affected by factors such as crystallinity, hydrophobic properties, and film thickness and integrity of the film components. All three precursor molecules of the composite film contain a large number of hydrophilic hydroxyl groups, which significantly increases the permeability coefficients of all substrate combinations, thereby limiting the application of the film to packaging of food with lower water content. SA and CMC are soluble in water, while CS is soluble in dilute acids. Adding a small amount of CMC has minimal effect on water absorption and the moisture permeability coefficient. Because SA has poor water resistance, the $\mathrm{SA}$ in the composite film was cross-linked using $\mathrm{a} \mathrm{CaCl}_{2}$ solution, leading to the formation of a gel network structure, which reduced the effect of water on the composite film. However, CS is also strongly affected by water; therefore, without a cross-linking treatment, the problem of high water absorption rate and moisture permeability coefficient of the composite film remains unsolved. $\mathrm{Hu}$ et al.'s study [28] showed that the mixing of CMC and CS led to a significant drop in WVP. This is the formation of hydrogen bonds between CS and CMC, which reduces the characteristics of the hydrophilic polysaccharide matrix. However, due to the added amount of CMC, the hydrophilicity of the composite membrane still exists. During the subsequent application of the composite film for the preservation of perishable fruits, it was discovered that the high moisture absorption and permeability helped absorb the moisture released during the respiration process of fresh fruit and prevented its spoilage. Noshirvani et al. [16] added cinnamon essential oil to the CS/CMC composite film. Studies indicated that the decrease in the WVP of CS/CMC composite films is due to hydrogen bonding between the biopolymers. The added cinnamon oil plasticizes the polysaccharide network of CS and 
$\mathrm{CMC}$, and improves the moisture permeability and oxidation resistance of the antimicrobial composite membrane. The composite film can be used for food preservation and improve food safety and quality. Bajpai et al. [18] proposed that the moisture absorption rate of the composite film is positively related to the content of CMC, while the composite film has strong moisture permeability. This is mainly due to the fact that $\mathrm{CMC}$ has a surface hydroxyl group and can easily adsorb water molecules, which renders that the $\mathrm{CMC}$ composite membrane hygroscopic. When water vapor enters the membrane matrix, the fluorene group in the cellulose chain does not interact with the invading water molecule owing to the strong internal triple bond interaction, and it exhibits good moisture permeability. This feature is important for preserving the freshness and extending the shelf life of fresh fruits.

The oil permeability of a film is related to the amount of lipophilic groups present in the film. The high oil permeability coefficient of the composite film is partially affected by SA, which contains a large number of lipophilic groups and ether groups. In addition, CS contains lipophilic groups and amino groups. Ebrahimzadeh et al. [37] proposed that the CMC composite film has good oxygen and lipid barrier properties. This conclusion is similar to that of [38]. However, owing to the small amount of CMC added to the composite membrane, the effect of CMC on the oil-repellent properties of the composite membrane is not significant. Therefore, the composite film has poor oil resistance that renders it suitable for packaging food that has low oil content. This also implies a decrease in the light transmittance rate of the composite film, which endows the film with an additional anti-oxidative effect [39]. This is consistent with the idea of Hu et al. [28] who suggested that transparency is one of the ideal features for food packaging films, and transparent films can see the packaged product. After adding the $\mathrm{CMC}$ to the blend film, the $\mathrm{CMC}$ may cause optical scattering and refraction, so the composite film transmittance decreases. However, it can shield some ultraviolet rays and prevent the photo-induced deterioration of packaged foods. Bonilla et al. [40] proposed that, owing to the presence of chitosan, the composite membrane is yellow, which limits the application of composite membranes.

\subsection{The Morphology of Films}

The surface morphologies of composite films were observed under electronic scanning microscope (SEM). Pure SA films have transparent crystals; however, after CS and CMC addition, the film transparency was reduced (Figure 1a). SEM images of the composite film demonstrated that the surface of the composite film is smooth, clean, and uniform (Figure 1b), indicating that the proportion and concentration used during the formation process facilitated even dispersion of CS and CMC within the polymer matrix, as well as good adhesion with the polymer matrix.

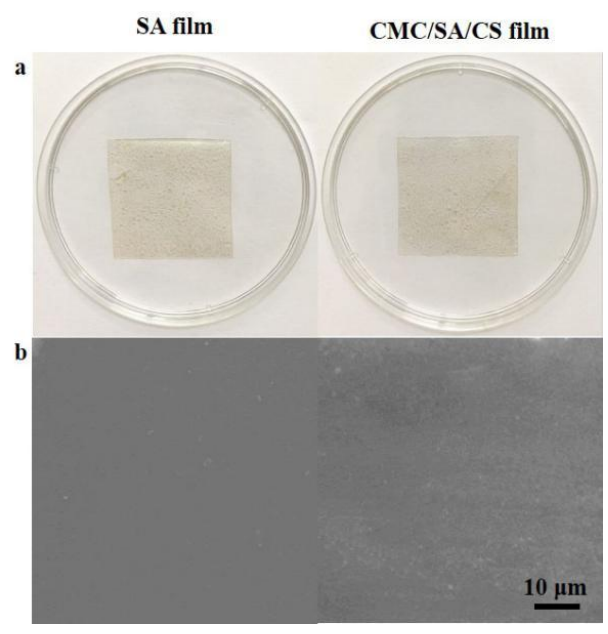

Figure 1. (a) Digital image of SA film and CMC/SA/CS film; (b) SEM images of SA film and CMC/SA/CS film. 


\subsection{FTIR Analysis}

Figure 2 presents the characteristic FTIR spectra corresponding to CS, SA, CMC, CMC/SA/CS. For the SA film, the bands at approximately $3300 \mathrm{~cm}^{-1}$ are assigned to the stretching vibrations of the hydroxyl group, respectively [41]. The band corresponding to asymmetric stretching vibrations of the methylene group occurs at approximately $2931 \mathrm{~cm}^{-1}$ [42]. The stretching vibration of the carboxylate anion $-\mathrm{COO}^{-}$exhibits two characteristic absorption peaks at 1590 and $1411 \mathrm{~cm}^{-1}$, corresponding to asymmetric and symmetric stretching vibration of the carboxylate group, respectively [43-45]. The band at approximately $1034 \mathrm{~cm}^{-1}$ corresponds to $\mathrm{C}-\mathrm{O}$ stretching in the acetyl groups present on the SA backbone [8]. This is similar to the results of Esteghlal et al. [46]. The characteristic absorption bands of $\mathrm{CMC}$ were detected at $1601 \mathrm{~cm}^{-1}$ and $1406 \mathrm{~cm}^{-1}$, which were the -COO asymmetric vibration and symmetric vibration absorption peak, respectively [8]. In the CS spectrum, The strong amino characteristic bands at $1588 \mathrm{~cm}^{-1}$ and $1324 \mathrm{~cm}^{-1}$ are assigned to amide I and amide II, respectively [43,47].

The spectra of CMC/SA/CS show clear increases in the intensity of the band strength is significantly wider and lower $3279 \mathrm{~cm}^{-1}$, attributed to the stretching vibration of CMC, SA hydroxyl group and the secondary amide group of CS. This may be due to the formation of hydrogen bonds between CMC, CS, and SA macromolecules. The formation of hydrogen bonds increases the degree of polarization of chemical bonds. Physical cross-linking between the surface-OH of the CMC and the -OH group of the $\mathrm{CS}$ molecule also consumes a small amount of $-\mathrm{OH}$ groups [16,47]. Followed by the $\mathrm{C}-\mathrm{H}$ stretching vibration peak at $2931 \mathrm{~cm}^{-1}$, the peak of the composite film almost disappeared, which may be related to the participation of $\mathrm{C}-\mathrm{H}$ in the $\mathrm{Na}^{+}$crosslinking reaction [47]. Finally, the $-\mathrm{COO}$ stretching vibration absorption peak at $1321 \mathrm{~cm}^{-1}$, the group pattern of the composite film becomes sharp, indicating that the composite film contains SA component, and is related to $\mathrm{CS}-\mathrm{NH}^{3+}$ protonation and hydration $[48,49]$. This is also related to the interaction between CS and CMC molecules [13]. In summary, the CS/SA/CMC composite film is not a simple physical mixture of ingredients, so it has great research value.

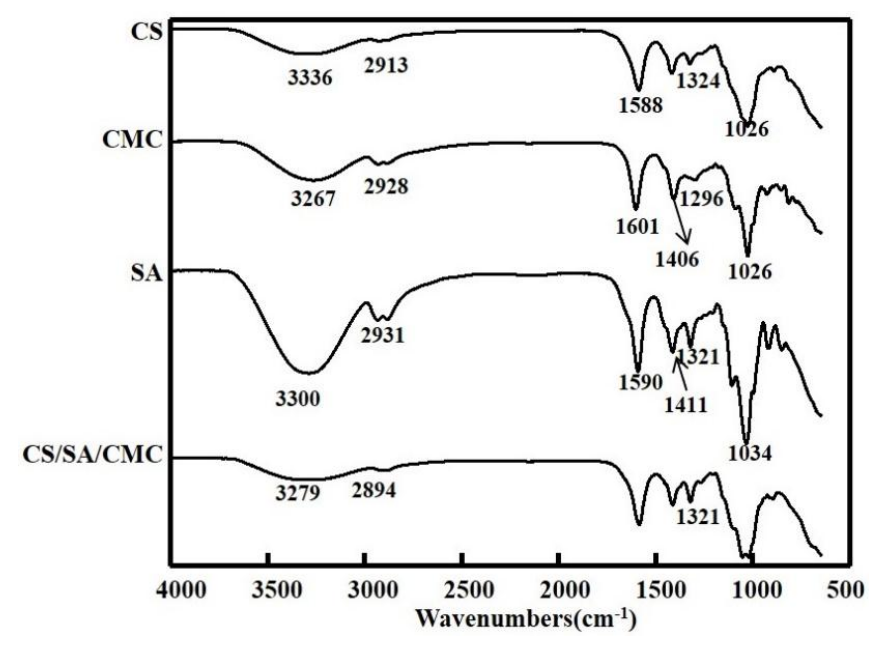

Figure 2. FTIR spectrum of CS, CMC, SA, and CMC/SA/CS fibers.

\subsection{Analysis of the Antibacterial Activity}

In the antibacterial activity test, the SA film was used as the negative control group. The composite films of the experimental groups were prepared using SA, CS, and CMC contents of $1.5 \%, 1.5 \%$, and $0.5 \%$, respectively, and tested against E. coli and S. aureus (Figure 3). The addition of CMC in the composite film may have an impact on the antibacterial properties, which is similar to that of $\mathrm{Hu}$ et al. [28]. They included CMC in quaternized chitosan (HTCC)-based films to develop antibacterial films for food preservation in order to meet the microbiological safety requirements for food packaging. The incorporation of CMC improved the tensile strength, thermal stability, and water resistance, 
but increased the oxygen permeability and reduced the antibacterial activity against gram-positive (S. aureus) and gram-negative (E. coli) bacteria. Further, the composite film could extend the shelf life of bananas. The antibacterial test results of our study are shown in Figure 3. The antibacterial rate of the composite film against $E$. coli is $95.7 \% \pm 5.4 \%$, while that against $S$. aureus is $93.4 \% \pm 4.7 \%$. These results indicate that the CMC/SA/CS composite film has an obvious inhibitory effect on the two bacterial strains. Figure 3 also reveals that the antibacterial performance of the composite film against $E$. coli is better than that against $S$. aureus. The same amount of CS exhibited stronger antibacterial performance against $E$. coli than against $S$. aureus, which is consistent with the conclusions of Ashraf et al. [50]. Being an organic antibiotic, CS can reduce or prevent bacterial adhesion and biofilm formation. The antibacterial mechanism of CS occurs by the promotion of the separation of microbial cell walls and films and destruction of the cell film by binding with the proteins in it; thus, the film loses its ability to control the incoming and outgoing substances [51]. Doulabi et al. [52] also reported the inhibition rate of CMC/SA/CS composite membrane against S. aureus to be $93.4 \%$. This difference may be related to the concentration of chitosan and the antibacterial properties of CMC to inhibit CS, which further validates the above conclusions.

Liu et al. [53] tested the antibacterial activity of PVA/CS composite membranes with different CS weight ratios on gram-negative (E. coli) and gram-positive (S. aureus) microorganisms. At the mass ratio of the composite membrane of PVA/CS-2.5, the composite membrane showed the best antibacterial effect. The antibacterial rate of PVA/CS membrane against $E$. coli and S. aureus were reported to be $98.8 \%$ and $99.16 \%$, respectively. The antibacterial activity of CS against gram-negative bacteria is better than that against gram-positive bacteria, which is contrary to the conclusion of this experiment. This may be attributed to the composition of the composite film and may also vary depending on the preparation method and conditions [54].

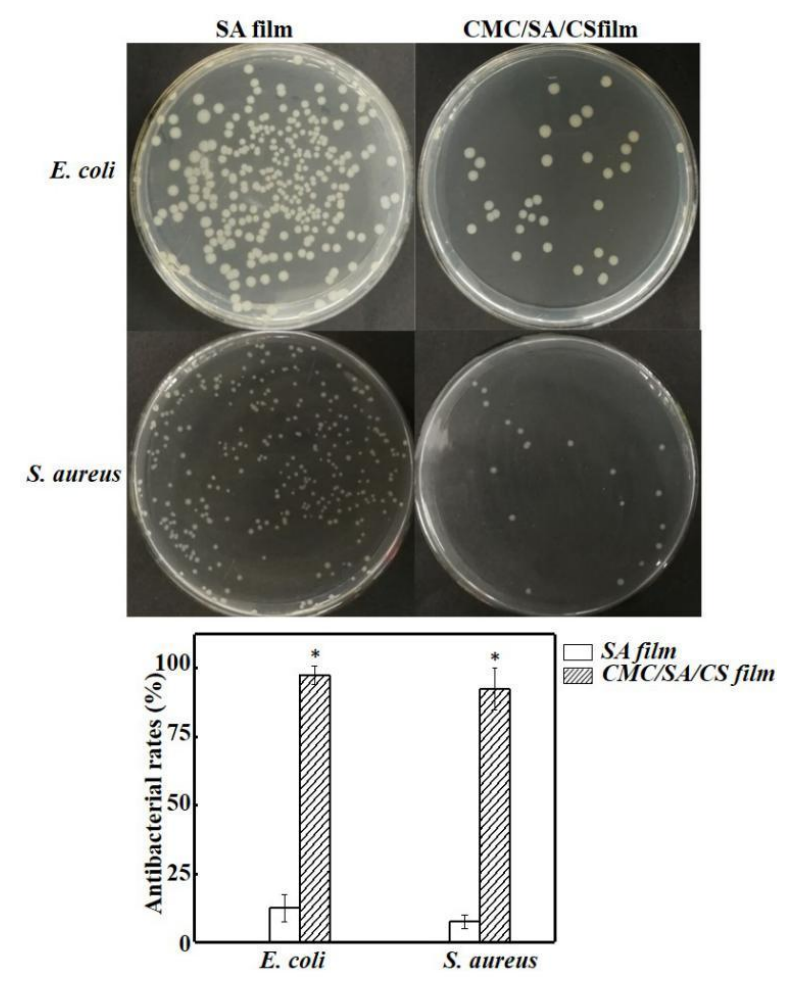

Figure 3. The antibacterial performance of the composite film against E. coli and S. aureus. $\left({ }^{*} p<0.05\right)$.

\subsection{Film Performance Comparison}

As mentioned earlier, SA has good film formation property, but it has strong water solubility, which limits the scope of development. CMC has a good internal network structure, but it cannot form 
a film by itself, without plasticizers. Chitosan has excellent antibacterial properties, but its membrane mechanical properties are poor. Each of the precursors, SA, CMC, and CS has its own defects, and many researchers have used them in combination to complement each other and expand the role of the field (Table 7). Such studies are remarkable, but new composite membranes consisting of SA, CMC, and CS are not studied well. Wang et al. [13] prepared HTCC/CMC composite membrane and found the tensile strength of the HTCC/CMC composite to be significantly higher than that of the pure film. When the mass ratio was $10 \%$, the tensile strength reached a maximum of $28.56 \mathrm{MPa}$. However, there is a negative relation between the tensile strength and elongation at break; the elongation at break decreases slightly to $2.27 \%$. Those improvements were attributed to the excellent compatibility between HTCC and CMC and strong electrostatic interaction between the molecules. Khazaei et al. [55] proposed that the elongation at break is closely related to the formation of a stable structure of biological macromolecules through hydrogen bonds or ionic bonds. The tensile strength of the composite film in this study can reach $65.32 \pm 14.31 \mathrm{MPa}$ and the elongation at break is $17.85 \% \pm 3.86 \%$, which is far beyond that of the pure HTCC film, pure CMC film, and HTCC/CMC composite film. This is mainly because, with the addition of $\mathrm{SA}$, which has good film formation ability and adhesion, the pores in the composite membrane can be fully filled and the tensile strength and elongation at break of the composite membrane can be improved. Hu et al. also prepared HTCC/CMC composite membranes; with the addition of $\mathrm{CMC}$, the tensile strength of the composite membranes increased from 2.06 to $45.56 \mathrm{MPa}$ and the elongation at break decreased from $246.36 \%$ to $8.08 \%$ [56]. Treenate et al. [57] developed a biomedical hydrogel film using hydroxyethyl acrylate chitosan (HC) and SA. The hydrogel film was reported to have a tensile strength and elongation of $12.1 \mathrm{MPa}$ and $162 \%$, respectively, which fully satisfy the reasonable mechanical properties and sufficient flexibility required during use. Han et al. [14] also prepared an antibacterial SA/CMC composite membrane. The composite film uses cinnamon essential oil as an antibacterial agent and glycerin as a plasticizer. The tensile strength and elongation at break of the SA/CMC composite film in the control group were reported to be $32.10 \mathrm{MPa}$ and $20.07 \%$, respectively. This may be related to the crystallinity of chitosan and also the amount of CMC added. However, the CMC/SA/CS composite membrane is superior to the CMC/SA membrane in terms of the tensile strength and antibacterial performance, and therefore, it is more promising. Overall, the tensile strength of the CMC/SA/CS composite membrane is better than those of all other previously reported composite membranes.

Table 7. Mechanical performance data summary.

\begin{tabular}{cccc}
\hline Film & Stress (MPa) & Strain (\%) & Reference \\
\hline SA/CMC & 32.10 & 20.07 & {$[14]$} \\
HTCC/CMC & $28.56 ; 45.56$ & $2.27 ; 8.08$ & {$[13,28]$} \\
SA/HC & 12.10 & 162.00 & {$[58]$} \\
CMC/SA/CS & $65.32 \pm 14.31$ & $17.85 \pm 3.86$ & Experiments \\
\hline
\end{tabular}

\section{Conclusions}

In this study, a novel food packaging material with antibacterial properties-CMC/SA/CS composite film - was prepared using a casting method. The orthogonal experimental design indicated that the optimal contents of the SA, CMC, and CS in the casting solution for the preparation of this composite film to be $1.5 \%, 0.5 \%$, and $1.5 \%$, respectively. This composition endowed the film with the most advantageous physical characteristics including the tensile strength, water vapor transmission rate, and elongation after fracture. The tensile strength of the optimized composite film is $65.32 \mathrm{MPa}$ and the elongation at break is $17.85 \%$. In view of the excellent performance and limitations of SA, $\mathrm{CMC}$, and CS for applications, there have been many researches on composite membranes with the combination of two or more of these. The tensile strength of the CMC/SA/CS composite film is significantly better than that of the two-two composite film. Although the tensile strength properties of the composite film are not significant, further research on such materials is required. However, the 
strength and ductility of the CMC/SA/CS composite film can meet the basic requirements of food packaging film. The prospect for the development of the composite film is promising. Moreover, the CMC/SA/CS composite film possesses good antibacterial properties, exhibiting an antibacterial rate of $95.7 \%$ against $E$. coli and $93.4 \%$ against $S$. aureus. Thus, the composite film has a promising future in antibacterial food packaging applications.

Author Contributions: Conceptualization, Y.L. and L.H.; Methodology, W.L.; Software, W.L.; Validation, W.L.; Formal Analysis, W.L.; Investigation, W.L.; Resources, W.L.; Writing-Original Draft Preparation, W.L.; Writing-Review \& Editing, W.L.; Visualization, Y.L. and L.H.; Project Administration, Y.L. and L.H.

Funding: This work was funded by National Natural Science Foundation of China (51703147), Science \& Technology Department of Sichuan Province (2018RZ0034), and Natural Science Fund of Education Department of Sichuan Province (16ZB0044 and 035Z1373).

Conflicts of Interest: The authors declare no conflict of interest.

\section{References}

1. Steinmetz, Z.; Wollmann, C.; Schaefer, M.; Buchmann, C.; David, J.; Troger, J.; Munoz, K.; Fror, O.; Schaumann, G.E. Plastic mulching in agriculture. Trading short-term agronomic benefits for long-term soil degradation. Sci. Total. Environ. 2016, 550, 690-705. [CrossRef] [PubMed]

2. Onwudili, J.A.; Williams, P.T. Catalytic supercritical water gasification of plastics with supported $\mathrm{RuO}_{2}$ : A potential solution to hydrocarbons-water pollution problem. Process Saf. Environ. Prot. 2016, 102, 140-149. [CrossRef]

3. Yang, S.; Lei, P.; Shan, Y.; Zhang, D. Preparation and characterization of antibacterial electrospun chitosan/poly (vinyl alcohol)/graphene oxide composite nanofibrous membrane. Appl. Surf. Sci. 2018, 435, 832-840. [CrossRef]

4. $\mathrm{Xu}, \mathrm{C}$;; Chen, $\mathrm{C}$; $\mathrm{Wu}, \mathrm{D}$. The starch nanocrystal filled biodegradable poly( $\varepsilon$-caprolactone) composite membrane with highly improved properties. Carbohydr. Polym. 2018, 182, 115-122. [CrossRef] [PubMed]

5. Xu, Q.; Chen, C.; Rosswurm, K.; Yao, T.; Janaswamy, S. A facile route to prepare cellulose-based films. Carbohydr. Polym. 2016, 149, 274-281. [CrossRef] [PubMed]

6. Deng, Y.; Song, X.; Ma, Z.; Zhang, X.; Shu, D.; Nan, J. $\mathrm{Al}_{2} \mathrm{O}_{3} /$ PVdF-HFP-CMC/PE separator prepared using aqueous slurry and post-hot-pressing method for polymer lithium-ion batteries with enhanced safety. Electrochim. Acta 2016, 212, 416-425. [CrossRef]

7. Yang, W.; Wang, J.; Yang, Q.; Pei, H.; Hu, N.; Suo, Y.; Li, Z.; Zhang, D.; Wang, J. Facile fabrication of robust MOF membranes on cloth via a CMC macromolecule bridge for highly efficient $\mathrm{Pb}$ (II) removal. Chem. Eng. J. 2018, 339, 230-239. [CrossRef]

8. Liu, S.; Li, Y.; Li, L. Enhanced stability and mechanical strength of sodium alginate composite films. Carbohydr. Polym. 2017, 160, 62-70. [CrossRef] [PubMed]

9. Varaprasad, K.; Raghavendra, G.M.; Jayaramudu, T.; Seo, J. Nano zinc oxide-sodium alginate antibacterial cellulose fibres. Carbohydr. Polym. 2016, 135, 349-355. [CrossRef] [PubMed]

10. Bano, S.; Mahmood, A.; Kim, S.J.; Lee, K.H. Chlorine resistant binary complexed NaAlg/PVA composite membrane for nanofiltration. Sep. Purif. Technol. 2014, 137, 21-27. [CrossRef]

11. Habiba, U.; Afifi, A.M.; Salleh, A.; Ang, B.C. Chitosan/(polyvinyl alcohol)/zeolite electrospun composite nanofibrous membrane for adsorption of $\mathrm{Cr}^{6+}, \mathrm{Fe}^{3+}$ and $\mathrm{Ni}^{2+}$. Sep. Purif. Technol. 2017, 322, 182-194. [CrossRef]

12. Ibarra, V.G.; Sendón, R.; de Quiros, A.R.-B. Antimicrobial food packaging based on biodegradable materials. Antimicrob. Food Packag. 2016, 363-384. [CrossRef]

13. Wang, B.; Yang, X.; Qiao, C.; Li, Y.; Li, T.; Xu, C. Effects of chitosan quaternary ammonium salt on the physicochemical properties of sodium carboxymethyl cellulose-based films. Carbohydr. Polym. 2018, 184, 37-46. [CrossRef] [PubMed]

14. Han, Y.; Yu, M.; Wang, L. Physical and antimicrobial properties of sodium alginate/carboxymethyl cellulose films incorporated with cinnamon essential oil. Food Pack. Shelf Life 2017, 15, 35-42. [CrossRef]

15. Kawasaki, T.; Nakaji-Hirabayashi, T.; Masuyama, K.; Fujita, S.; Kitano, H. Complex film of chitosan and carboxymethyl cellulose nanofibers. Colloids Surf. B 2016, 139, 95-99. [CrossRef] [PubMed] 
16. Noshirvani, N.; Ghanbarzadeh, B.; Gardrat, C.; Rezaei, M.R.; Hashemi, M.; Le Coz, C.; Coma, V. Cinnamon and ginger essential oils to improve antifungal, physical and mechanical properties of chitosan-carboxymethyl cellulose films. Food Hydrocolloid 2017, 70, 36-45. [CrossRef]

17. Zhuang, C.; Jiang, Y.; Zhong, Y.; Zhao, Y.; Deng, Y.; Yue, J.; Wang, D.; Jiao, S.; Gao, H.; Chen, H.; et al. Development and characterization of nano-bilayer films composed of polyvinyl alcohol, chitosan and alginate. Food Control 2018, 86, 191-199. [CrossRef]

18. Bajpai, S.K.; Chand, N.; Ahuja, S. Investigation of curcumin release from chitosan/cellulose micro crystals (CMC) antimicrobial films. Int. J. Boil. Macromol. 2015, 79, 440-448. [CrossRef] [PubMed]

19. Wang, Y.; Zheng, Y.; He, W.; Wang, C.; Sun, Y.; Qiao, K.; Wang, X.; Gao, L. Reprint of: Preparation of a novel sodium alginate/polyvinyl formal composite with a double crosslinking interpenetrating network for multifunctional biomedical application. Compos. Part B Eng. 2017, 121, 9-22. [CrossRef]

20. Ahmed, S.; Ikram, S. Chitosan and gelatin based biodegradable packaging films with UV-light protection. J. Photochem. Photobiol. B 2016, 163, 115-124. [CrossRef] [PubMed]

21. Yu, Z.; Alsammarraie, F.K.; Nayigiziki, F.X.; Wang, W.; Vardhanabhuti, B.; Mustapha, A.; Lin, M. Effect and mechanism of cellulose nanofibrils on the active functions of biopolymer-based nanocomposite films. Food Res. Int. 2017, 99, 166-172. [CrossRef] [PubMed]

22. Ercelik, M.; Ozden, A.; Devrim, Y.; Colpan, C.O. Investigation of Nafion based composite membranes on the performance of DMFCs. Int. J. Hydrogen Energy 2017, 42, 2658-2668. [CrossRef]

23. Xie, J.; Zhang, K.; Wu, J.; Ren, G.; Chen, H.; Xu, J. Bio-nanocomposite films reinforced with organo-modified layered double hydroxides: Preparation, morphology and properties. Appl. Clay Sci. 2016, 126, 72-80. [CrossRef]

24. Wang, P.; Wang, H.; Liu, J.; Wang, P.; Jiang, S.; Li, X.; Jiang, S. Montmorillonite@chitosan-poly(ethylene oxide) nanofibrous membrane enhancing poly(vinyl alcohol-co-ethylene) composite film. Carbohydr. Polym. 2018, 181, 885-892. [CrossRef] [PubMed]

25. Kida, T.; Ohta, T.; Kondo, K.; Akashi, M. Fabrication of poly(vinyl alcohol)s (PVAs) nanotubes through the fusion of nanocapsules composed of PVAs multilayer films. Polymer 2014, 55, 2841-2847. [CrossRef]

26. Liu, Y.; Ji, P.; Lv, H.; Qin, Y.; Deng, L. Gentamicin modified chitosan film with improved antibacterial property and cell biocompatibility. Int. J. Biol. Macromol. 2017, 98, 550-556. [CrossRef] [PubMed]

27. Nouri, A.; Yaraki, M.T.; Ghorbanpour, M.; Agarwal, S.; Gupta, V.K. Enhanced antibacterial effect of chitosan film using Montmorillonite/CuO nanocomposite. Int. J. Biol. Macromol. 2017, 109, 1219-1231. [CrossRef] [PubMed]

28. Hu, D.; Wang, H.; Wang, L. Physical properties and antibacterial activity of quaternized chitosan/carboxymethyl cellulose blend films. LWT-Food Sci. Technol. 2016, 65, 398-405. [CrossRef]

29. Zhang, Y.; Sun, G.; Wang, X.; Wang, L.; Hu, M.; Wang, Z.; Tao, Y. Efforts on membrane properties and enzymes by adding divalent cations and sodium carboxymethyl cellulose. Carbohydr. Polym. 2014, 106, 94-100. [CrossRef] [PubMed]

30. Zhivkov, A.M.; Hristov, R.P. Adsorption of carboxymethyl cellulose on alumina particles. J. Colloid Interface Sci. 2015, 447, 159-166. [CrossRef] [PubMed]

31. Vild, A.; Teixeira, S.; Kühn, K.; Cuniberti, G.; Sencadas, V. Orthogonal experimental design of titanium dioxide-poly(methyl methacrylate) electrospun nanocomposite membranes for photocatalytic applications. J. Environ. Chem. Eng. 2016, 4, 3151-3158. [CrossRef]

32. Ebrahimi, B.; Mohammadi, R.; Rouhi, M.; Mortazavian, A.M.; Shojaee-Aliabadi, S.; Koushki, M.R. Survival of probiotic bacteria in carboxymethyl cellulose-based edible film and assessment of quality parameters. LWT-Food Sci. Technol. 2018, 87, 54-60. [CrossRef]

33. Atef, M.; Rezaei, M.; Behrooz, R. Preparation and characterization agar-based nanocomposite film reinforced by nanocrystalline cellulose. Int. J. Biol. Macromol. 2014, 70, 537-544. [CrossRef] [PubMed]

34. Cheng, B.; Li, D.; Huo, Q.; Zhao, Q.; Lan, Q.; Cui, M.; Pan, W.; Yang, X. Two kinds of ketoprofen enteric gel beads (CA and CS-SA) using biopolymer alginate. Asian J. Pharm. Sci. 2017, 13, 120-130. [CrossRef]

35. Kingkaew, J.; Kirdponpattara, S.; Sanchavanakit, N.; Pavasant, P.; Phisalaphong, M. Effect of molecular weight of chitosan on antimicrobial properties and tissue compatibility of chitosan-impregnated bacterial cellulose films. Biotechnol. Bioprocess E 2014, 19, 534-544. [CrossRef]

36. Kanmani, P.; Lim, S.T. Development and characterization of novel probiotic-residing pullulan/starch edible films. Food Chem. 2013, 141, 1041-1049. [CrossRef] [PubMed] 
37. Ebrahimzadeh, S.; Ghanbarzadeh, B.; Hamishehkar, H. Physical properties of carboxymethyl cellulose based nano-biocomposites with graphene nano-platelets. Int. J. Biol. Macromol. 2016, 84, 16-23. [CrossRef] [PubMed]

38. Paunonen, S. Nanocellulose-based food packaging materials-A review. Nord. Pulp Pap. Res. J. 2013, 28, 165-181. [CrossRef]

39. Souza, V.G.L.; Fernando, A.L.; Pires, J.R.A.; Rodrigues, P.F.; Lopes, A.A.S.; Fernandes, F.M.B. Physical properties of chitosan films incorporated with natural antioxidants. Ind. Crop. Prod. 2017, 107, 565-572. [CrossRef]

40. Bonilla, J.; Talon, E.; Atares, L.; Vargas, M.; Chiralt, A. Effect of the incorporation of antioxidants on physicochemical and antioxidant properties of wheat starchechitosan films. J. Food Eng. 2013, 118, 271-278. [CrossRef]

41. Sheela, T.; Bhajantri, R.F.; Nambissan, P.M.G.; Ravindrachary, V.; Lobo, B.; Naik, J.; Rathod, S.G. Ionic conductivity and free volume related microstructural properties of $\mathrm{LiClO}_{4} / \mathrm{PVA} / \mathrm{NaAlg}$ polymer composites: Positron annihilation spectroscopic studies. J. Non-Cryst. Solids 2016, 454, 19-30. [CrossRef]

42. Sheela, T.; Bhajantri, R.F.; Ravindrachary, V.; Rathod, S.G.; Pujari, P.K.; Poojary, B.; Somashekar, R. Effect of UV irradiation on optical, mechanical and microstructural properties of PVA/NaAlg blends. Radiat. Phys. Chem. 2014, 103, 45-52. [CrossRef]

43. Li, J.; Ma, J.; Chen, S.; He, J.; Huang, Y. Characterization of calcium alginate/deacetylated konjac glucomannan blend films prepared by $\mathrm{Ca}^{2+}$ crosslinking and deacetylation. Food Hydrocolloids 2018, 82, 363-369. [CrossRef]

44. Gholizadeh, B.S.; Buazar, F.; Hosseini, S.M.; Mousavi, S.M. Enhanced antibacterial activity, mechanical and physical properties of alginate/hydroxyapatite bionanocomposite film. Int. J. Biol. Macromol. 2018, 116, 786-792. [CrossRef] [PubMed]

45. Akhtar, H.M.S.; Riaz, A.; Hamed, Y.S.; Abdin, M.; Chen, G.; Wan, P.; Zeng, X. Production and characterization of CMC-based antioxidant and antimicrobial films enriched with chickpea hull polysaccharides. Int. J. Biol. Macromol. 2018, 118, 469-477. [CrossRef] [PubMed]

46. Esteghlal, S.; Niakousari, M.; Hosseini, S.M.H. Physical and mechanical properties of gelatin-CMC composite films under the influence of electrostatic interactions. Int. J. Biol. Macromol. 2018, 114, 1-9. [CrossRef] [PubMed]

47. Shankar, S.; Rhim, J.W. Preparation and characterization of agar/lignin/silver nanoparticles composite films with ultraviolet light barrier and antibacterial properties. Food Hydrocolloids 2017, 71, 76-84. [CrossRef]

48. Ren, H.; Gao, Z.; Wu, D.; Jiang, J.; Sun, Y.; Luo, C. Efficient Pb(II) removal using sodium alginate-carboxymethyl cellulose gel beads: Preparation, characterization, and adsorption mechanism. Carbohydr. Polym. 2016, 137, 402-409. [CrossRef] [PubMed]

49. Zhu, T.; Luo, Y.; Lin, Y.; Li, Q.; Yu, P.; Zeng, M. Study of pervaporation for dehydration of caprolactam through blend NaAlg-poly(vinyl pyrrolidone) membranes on PAN supports. Sep. Purif. Technol. 2010, 74, 242-252. [CrossRef]

50. Branca, C.; D’Angelo, G.; Crupi, C.; Khouzami, K.; Rifici, S.; Ruello, G.; Wanderlingh, U. Role of the OH and $\mathrm{NH}$ vibrational groups in polysaccharide-nanocomposite interactions: A FTIR-ATR study on chitosan and chitosan/clay films. Polymer 2016, 99, 614-622. [CrossRef]

51. Ashrafi, A.; Jokar, M.; Nafchi, A.M. Preparation and characterization of biocomposite film based on chitosan and kombucha tea as active food packaging. Int. J. Biol. Macromol. 2018, 108, 444-454. [CrossRef] [PubMed]

52. Campana, R.; Casettari, L.; Ciandrini, E.; Illum, L.; Baffone, W. Chitosans inhibit the growth and the adhesion of klebsiella pneumonia and escherichia coli clinical isolates on urinary catheters. Int. J. Antimicrob. Agents 2017, 50, 135-141. [CrossRef] [PubMed]

53. Doulabi, A.H.; Mirzadeh, H.; Imani, M.; Samadi, N. Chitosan/polyethylene glycol fumarate blend film: Physical and antibacterial properties. Carbohydr. Polym. 2013, 92, 48-56. [CrossRef] [PubMed]

54. Liu, Y.; Wang, S.; Lan, W. Fabrication of antibacterial chitosan-PVA blended film using electrospray technique for food packaging applications. Int. J. Biol. Macromol. 2017, 107, 848-854. [CrossRef] [PubMed]

55. Rafique, A.; Zia, K.M.; Zuber, M.; Tabasum, S.; Rehman, S. Chitosan functionalized poly(vinyl alcohol) for prospects biomedical and industrial applications: A review. Int. J. Biol. Macromol. 2016, 87, 141-154. [CrossRef] [PubMed] 
56. Khazaei, N.; Esmaiili, M.; Djomeh, Z.E.; Ghasemlou, M.; Jouki, M. Characterization of new biodegradable edible film made from basil seed (Ocimum basilicum L.) gum. Carbohydr. Polym. 2014, 102, 199-206. [CrossRef] [PubMed]

57. Schreiber, S.B.; Bozell, J.J.; Hayes, D.G.; Zivanovic, S. Introduction of primary antioxidant activity to chitosan for application as a multifunctional food packaging material. Food Hydrocolloids 2013, 33, 207-214. [CrossRef]

58. Treenate, P.; Monvisade, P.; Yamaguchi, M. Development of hydroxyethylacryl chitosan/alginate hydrogel films for biomedical application. J. Polym. Res. 2014, 21, 601. [CrossRef] 